\title{
General Principles of the Physiotherapy Treatment of Diseases of the Heart.
}

\author{
by Miss JEAN BLAIR, M.C.S.P., T.M.M.G., T.E.T. \\ Senior Lecturer, University of the Witwatersraud.
}

$\mathbf{P}$ HYSIOTHERAPY in cardiac disease is used far too infrequently and its advantages are not generally recognised.

This seems a pity when it is so important in these days of bed shortage and limited staffing problems to make every endeavour to assist patients to recover as quickly as possible, particularly those suffering from chronic conditions.

Not all medical cardiac conditions are suitable for treatment, and there are odd cases where the psychological reaction of the patient makes him or her unco-operative, as some people are resigned to a life of invalidism under any condition.

If a suitable cardiac is given early conscientious physiotherapy, it has been proved that the convalescent stage can be greatly shortened and the final tolerance to exercise in many cases is such that with normal precautions an active and happy life can be led. (This does not mean that every cardiac can rush off and play a hard game of tennis!)

It must always be remembered that to "undertreat" a cardiac case is not only a waste of time, but does not enhance the reputation of the physiotherapist nor the value of physiotherapy.

The first essential is to assess the stage of convalescence which the patient has reached, and the patient's own tolerance. This can rarely be done in a single treatment and until treatment is sufficient to raise the tolerance, the course has not begun. Far too often, a congestive cardiac failure patient receives massage and passive movements only to within days or even hours of becoming ambulatory.

The principles and brief outline given below are no more than a skeleton, but may help to convey that:

(a) Cardiac patients are worth treating;

(b) Graduated treatment is essential and must be progressed skilfully;

(c) Assessment of exercise tolerance is the keynote, and

(d) Undertreatment is a crime.

Conditions not suitable for physical treatment:

1. Pericarditis-danger of permanent destruction.

2. Coronary Thrombosis-early stages.

3. Acute Myocarditis.

4. Acute Endocarditis.

5. Subacute Endocarditis.

6. Angina.

7. Rheumatic Fever.

Conditions suitable for physical treatment:

1. Subacute Myodcarditis and Fndocarditis.

2. Chronic Myocarditis.

3. Chronic insufficiency.

4. Congestive failure.

4. Congestive failure.

5. Cor. Pulmonali.

6. Disordered Action of the Heart.

Times for the commencement of treatment:

1. Bacterial lesions-When the temperature is steady and not more than $100^{\circ}$ for 3 weeks.
Dangers - a sudden rise in temperature. a steadily rising resting pulse.

2. Cardiac Insufficiences-massage and passive exercises immediately.

Active exercises when oedema is subsiding and urine output rising.

3. Cor Pulmonale-immediately, breathing may be given with $\mathrm{O}_{2}$ therapy.

4. Coronary Thrombosis-depends on the Physician.

General Rules for Physical Treatment:

1. Pulse-before and after: $1 \mathrm{~min}$. before, 2 mins. after.

Apex beat to be taken in Auricular fibrillation.

2. 1st Treatment-Maximum of $\mathbf{1 0}$ minutes treatment.

3. Progress - in time, speed and resistance. early stages all exercises are free, no resistance.

4. Watch temperature and pulse chart, count respirations.

NOTE.-If temperature rises stop all work. If pulse irregular reduce work.

5. Watch for fatigue.

Aims of Physical Treatment:

1. To increase the Oxygen intake.

2. To increase the exercise tolerance.

3. To reassure the patient.

4. To strengthen all muscles and hasten ambulation.

General method of teatment:

1. MASSAGE.

(a) Acute-brisk and light-to prepare muscles progression slow.

(b) Chronic-slow and deep to drain tissues. Progression rapid.

2. PASSIVE MOVEMENTS.

(a) Acute-fairly rapid.

(b) Chronic-slow to assist venous return.

3. ACTIVE EXERCISES-Directed at complete compensation.

(a) Acute-begun after the temperature has been below $100^{\circ}$ for 3 weeks.

(b) Chronic--begun when the oedema is subsiding, and urine output up.

General Method of Progress:

WRIST \& ANKLE.-Bending and stretching or circumduction. Times: Starting with 6 , progressing by 3 to 20 maximum.

ELBOWS, \& KNEES + HIPS.-Bending and stretching. Times: Starting with 6, progressing by 2 to 30 times a minute for 3 minutes.

SHOULDERS.-As for Hip and Knee.

NOTE.-When Shoulder and Hip exercises are introduced massage is discontinued.

TRUNK:

(a) Side flexion or rotation. Times: Starting with 4, progressing to 12 maximum.

(b) Add according to rate of progress. Forward flexion and finally extension.

(c) Trunk exercises are stopped when walking begun. 


\section{WALKING :}

(a) Begun when trunk exercises established. Times: 1st, round the bed, thereafter-1 ward length and progress to climbing stairs.

Assessment of Patient's tolerance:

1. PRIVILEGES: (i.e.) Complete bedrest or

(a) Washing.

(b) Feeding.

(c) Sitting up out of bed.

2. TEST EXERCISES-to be given at end of each day during bed stage. Pulse should rise at the end of all tables for the minimum of 8 beats.

NOTE.-Pulse must return to resting count after 2 minutes maximum.

3. PULSE RATIO.-Used only after patient is ambulatory:

Pulse: 2 mins after

$$
1 \mathrm{~min} \text {. before }
$$

Normal ratio $=2,3$.

Normal Test $=$ running on spot $30 \mathrm{sec}$. or on and - off 12-in: stool $25-30$ times.

All cardiac physical treatment is based on the individual patient's tolerance. It is difficult to assess this at the first treatment, and is dependent on:

(b) Pulse rise and resting time.

(c) General mental outlook of patient.

(d) Speed of progress.

NOTE.-Digitalis: If this drug is being administered, more care must be taken because the pulse is then not a true indication of the patient's tolerance to exercise.

\section{EXAMPLES OF CARDIAC TABLES:}

1. EARLY Pulse before 90.

1. Massage 5 mins. to each leg to knee.

2. Passive movements to foot and knee 10 times each.

3. Breathing to patient's own count encouraging slower and deeper rhythm. Pulse after 1st $\min .=102 ;$ 2nd $\min$. $=88$.

Progression Add wrist and elbow during following 2 days. Then progress in numbers and gradually introduce active work.

2. APPROX.: 2 weeks after compensation begun:

(a) Breathing (to patient's own time)

(b) Ankle rolling 15 times.

(c) Wrist flex and extend 10 times.

(d) Hip and knee flex and extend 10 times.

(e) Elbow flex and extend 6 times.

(f) Breathing 4 or 5 times,

-Pulse 2 minutes.

3. AN EARLY AMBULATORY TABLE:

(a) Breathing.

(b) Hip and knee flex and extend 30 times per minute for 3 mins.

(c) Head roll 4 times in each direction.

(d) Arms bend and stretch 10 times.

(e) Back raise vertebra by vertebra $\times 2$.

(f) Sitting on side of bed, alternate ankle flex and extend 10 times.

(g) Walking 18 paces.

Pulse 2 minutes.

\section{MODIFICATIONS:}

Cor Pulmonale: This is the result of a Respiratory Disease and is therefore treated as such.

Emphasis must be laid on breathing and in particular Diaphragmatic breathing, and in most cases the condition can be improved if the patient can tolerate percussion of the chest, with or without a modified postural drainage.

If the lung congestion can be relieved this will alleviate the work of the heart and cause relief and a general improvement in the condition.

Prognosis.-In this condition the prognosis is poor.

D.A.H.-This condition is normally classified as a neurosis and is treated as such, but a general scheme of postural and strengthening exercises assist the patient in re-adjusting himself to normality. The exercises can where possible be given in a class to stimulate the competitive spirit and improve the morale.

Coronary Thrombosis.-Progression in. this case is rapid, but the tolerance exercises given at a slower pacc than in cases of compensatory hearts.

\section{PERSONAL}

Mrs. D. Courlander is working in Bulawayo for the Rhodesian Society for the Blind and Physically Handicapped. She finds the work in this up-to-date Clinic extremely rewarding and interesting, and any members of the Society will be most welcome to visit it, especially if they can offer advice or criticism to this young organisation.

Miss E. Betts, Miss M. Rodwell, and Miss M. Howe have left the staff of Johannesburg Hospital to go to England.

Miss A. Zuithoff and Miss M. Iuel have joined the Johannesburg Hospital staff. They have recently arrived from Holland and Denmark respectively.

Miss Barbara Viney is now working in private practice in Johannesburg.

Miss Jean Scott-Russell is marrying Mr. Jack Lugg on April 2nd in Krugersdorp.

Miss J. Jersing, who has recently arrived from Denmark, is to work for a physical medicine specialist in Durban.

Miss Chenik, who is now working at Krugersdorp, is congratulated on her engagement.

Mrs. Killen and Miss Rehfeld are welcomed to the staff of the Pretoria Hospital Physiotherapy School. fontein.

Mrs. Steyn (neé Sonnenberg) is now living in Bloem-

Miss Potgieter has married and is now Mrs. Jooste.

Mrs. Dawson (nee Golden) is working at the Hospital in Salisbury, Southern Rhodesia.

Miss Klooster and Miss Steenkamp are both working at Voortrekkerhoogte Hospital.

Miss van Heerden is working at the Andrew McColm Hospital, Pretoria.

Miss Kotze is working at the Addington Hospital, Durban.

New members of the Pretoria Hospital staff are welcomed: Mrs. Evans (neé Marais), Miss de Jager, Mrs. Meidlinger, Miss Kok and Miss Booysen.

Miss Junack and Miss van der Merwe have left for Cape Town.

Congratulations to Mrs. Osche (neè van Weillich) on the birth of a daughter.

Miss H. Baines, Miss J. Blair, Mss. S. Bold, Miss M. Hinz and Mrs. G. Taylor have been appointed to the Transvaal Provincial Roll of Teachers of Physiotherapy. 